\title{
FLEXIBILIZAÇÃO DAS LEIS TRABALHISTAS E AS CONSEQUENCIAS PARA O TRABALHADOR
}

\author{
FLEXIBILIZATION OF LABOR LAWS AND CONSEQUENCES FOR WORKER
}

Daniela Monteiro TREVIZANI ${ }^{1}$

ISSUE DOI: 10.21207/2675-0104.2017.667

\begin{abstract}
RESUMO
O presente trabalho teve como finalidade analisar a flexibilização dos direitos trabalhistas e a violação nos direitos e garantias fundamentais dos trabalhadores. Sob um ponto de vista etimológico e jurídico, flexibilizar é tornar flexível, maleável. Assim sendo, flexibilizar o Direito do Trabalho é torna-lo menos rígido. Sob um ponto de vista estritamente conceitual, flexibilização representa a adaptação das regras jurídicas a uma nova realidade, gerando um novo tipo de regulamentação. O presente trabalho tem grande relevância, haja vista o momento econômico em que o Brasil se encontra. Isto porque a Flexibilização dos direitos trabalhistas foi decorrente, dentre outros fenômenos, da crise econômica vivenciada no início da década de 1970. Como se faz visível em todo período drástico do ponto de vista econômico e social, surgem nos dias atuais, correntes com o intuito de suprimir direitos da classe trabalhadora, os quais foram conquistados através com grande dificuldade e, por este modo, não devem ser enfraquecidos. A pesquisa teve o enfoque em métodos como o de caráter dedutivo, onde foi feita uma análise da ideia geral, a "Flexibilização da jornada de trabalho e sua violação nos direitos e garantias fundamentais dos trabalhadores", como estrutura basilar foi utilizado uma concepção histórica com intuito comparativo, tecendo análises entre os diversos períodos políticos e sociais brasileiros até a fase contemporânea, bem como o método bibliográfico através da análise doutrinária.
\end{abstract}

Palavras-chaves: Flexibilização. Precarização. Direito do Trabalho. Direitos e Garantias Fundamentais.

\section{ABSTRACT}

\footnotetext{
${ }^{1}$ Discente da Faculdade de Direito de Franca/SP. Bolsista do Programa Interno de Iniciação Cientítica (PIBIC 2016-2017).
} 
The purpose of this study was to analyze the flexibilization of labor rights and the violation of workers' fundamental rights and guarantees. From an etymological and le gal point of view, flexibility is flexible and malleable. Therefore, making labor law more flexible is to make it less rigid. From a strictly conceptual point of view, flexibility represents the adaptation of the legal rules to a new reality, generating a new type of regulation. The present work has great relevance, given the economic moment in which Brazil finds itself. This is because the flexibilization of labor rights was due, among other phenomena, to the economic crisis experienced in the early 1970s. As it becomes visible in every drastic period from an economic and social point of view, they arise in the current day, currents with the intention of suppressing the rights of the working class, which were conquered through great difficulty, and thus should not be weakened. The research focused on methods such as deductive methods, where an analysis of the general idea was made, "Flexibilization of the working day and its violation of workers' fundamental rights and guarantees". Comparative analysis, weaving analyzes between the different Brazilian political and social periods up to the contemporary phase, as well as the bibliographic method through the doctrinal analysis.

Keywords: Flexibility. Precariousness. Labor law. Fundamental Rights and Guarantees.

\section{INTRODUÇÃO}

No curso da história as formas de trabalho foram se modificando para se adequar a realidade, surgindo a necessidade de se transformar as leis laborais que eram fortemente direcionadas à proteção dos trabalhadores. Com a evolução da economia, principalmente com a globalização, surgiram inovações quanto às formas de trabalho, aos horários e à contratação de mão de obra, acarretando no surgimento de novos fenômenos tais como a flexibilização, desregulamentação, terceirização, que de certa forma trouxeram insegurança para o trabalhador.

Sob um ponto de vista etimológico e jurídico, flexibilizar é tornar flexível, maleável. Assim sendo, flexibilizar o Direito do Trabalho é tornalo menos rígido. Sob um ponto de vista estritamente conceitual, flexibilização representa a adaptação das regras jurídicas a uma nova realidade, gerando um novo tipo de regulamentação.

A generalização da flexibilização do sistema produtivo capitalista surgiu em meados do século XX com o objetivo de satisfazer as necessidades das empresas, tendo influenciado tanto no modelo produtivo, como também, por consequência, o direito de regência destas relações pertinentes à produção, sobretudo as trabalhistas, passando a ser palavra de ordem tornar menos rígida a prestação de trabalho, as relações que sustentam tal prestação e o direito que as regula ${ }^{2}$.

\footnotetext{
${ }^{2}$ BELTRAMELLI, Neto, Silvio. Limites da flexibilização dos direitos trabalhistas. São Paulo: LTR, 2008.
} 
Alice Monteiros de Barros $^{3}$ afirma em sua obra que os fatores da flexibilização foram a crise econômica do início da década de 1970, gerada pelo alto preço do petróleo, bem como a inovação da tecnologia, da qual decorreram modificações intensas na organização da produção, aumento da concorrência com os países orientais e a necessidade de se combater o desemprego em massa denominado "desemprego estrutural".

Com as crises econômicas cada vez mais frequentes, torna-se comum criticas quanto à rigidez da legislação trabalhista, fato amplamente perigoso tendo em vista que as práticas de flexibilização podem acarretar um barateamento da mão de obra, atingindo também outros direitos trabalhistas tais como férias, descanso semanal, adicionais etc. Diante destas propostas é fácil imaginar as fortes tensões produzidas na estrutura normativa laboral, o que proporcionaria uma diminuição dos direitos estabelecidos na Constituição Federal, sendo de extrema necessidade o respeito aos princípios fundamentais. Por conseguinte, no cenário econômico atual, não se pode existir medidas impensadas, que mesmo aparentando ser uma forma de se impulsionar a economia, acabaria apenas por aumentar o ciclo de crises devido às condições precárias dos "consumidores-trabalhadores".

A Flexibilização dos direitos trabalhistas foi decorrente, dentre outros fenômenos, da crise econômica vivenciada no início da década de 1970. Como se faz visível em todo período drástico do ponto de vista econômico e social, surgem nos dias atuais, correntes com o intuito de suprimir direitos da classe trabalhadora, os quais foram conquistados através com grande dificuldade e, por este modo, não devem ser enfraquecidos.

Em meio a pressões de neoliberais, está ocorrendo uma busca por se limitar direito por direito, encurtando a proteção das normas perante os trabalhadores. Há um forte aumento nos discursos pró-flexibilização, apoiado na ideia de ser este o único caminho para se conseguir superar as crises econômicas, já que apenas deste modo existiria a possibilidade de se manter vários trabalhadores empregados. Todavia, o rumo que tais medidas podem tomar é o de precarização não só das relações de trabalho, como dos direitos e garantias fundamentais.

\footnotetext{
${ }^{3}$ BARROS, Alice Monteiro. Curso de direito do trabalho. São Paulo :LTR, 2005.
} 
Jorge Luiz Souto Maior" leciona que a flexibilização "encontra vários obstáculos jurídicos, já que o princípio protetivo do trabalhador está positivado em várias constituições e mesmo na Declaração de Filadélfia". A flexibilização tem sido utilizada como pretexto para combater o desemprego, sendo uma forma de proteger outro direito social fundamental, o direito ao trabalho, além do que "seria melhor uma flexibilização controlada a uma flexibilização de fato, sem qualquer controle". Entretanto, na Espanha, com a "Reforma Trabalhista" de 1994, com o intuito de resolver o problema do desemprego com a flexibilização das normas trabalhistas, ocorreu o inverso, ou seja, a situação do desemprego agravou, "na medida em que o próprio emprego se transformou em um emprego precário e de pouca duração".

Outro fundamento utilizado para a flexibilização na negociação coletiva é o da manutenção de empregos. O problema é que a ameaça do desemprego afeta somente uma das partes da negociação, os trabalhadores, os quais se sentem "coagidos" a ceder e aceitar a redução de seus direitos, não havendo assim, a contrapartida, que é um dos requisitos essenciais para a flexibilização. "Essa ideia da unilateralidade da perda fragiliza a negociação e reverte à tendência para a da concretização de uma falsa flexibilização", criando a ilusão de que "a diminuição dos direitos sociais seria uma boa para os trabalhadores". Entretanto, "esta vantagem não se consubstancia em realidade, na medida em que a diminuição dos direitos sociais não corresponde necessariamente ao aumento dos empregos". Desta forma, a verdadeira flexibilização só existe com a contrapartida, ou seja, nela "ambas as partes devem ganhar e perder para que exista a pretendida criação de postos de serviços" 5 .

Além do mais, "a flexibilização do Direito do Trabalho não é uma solução ao desemprego, contribuindo normalmente apenas para agraválo". Ela gera diversos problemas, tais como a "rotatividade da mão de obra, a insegurança social, a carência de especialização e a falta de investimento das empresas nos trabalhadores, a redução do patamar salarial, o enfraquecimento do sindicato". E com isso há reflexos negativos na própria

\footnotetext{
${ }^{4}$ MAIOR, Jorge Luiz Souto. O direito do trabalho como instrumento da justiça social. São Paulo: saraiva 2009. p.166 e 181.

${ }^{5}$ CORREIA, Marcos Orione Gonçalves. Flexibilização com Fair Play. Revista LTr, São Paulo, ano 65 , n. 09 , set. 2001, p. 1048-149.
} 
atividade das empresas e no desenvolvimento econômico do país, que "restam prejudicados"6.

Diante destes reflexos negativos para os trabalhadores e para as próprias empresas é que se vê necessária a limitação da flexibilização na negociação coletiva. Todos os países em que se reconhece a proteção do trabalhador "integra o sistema dos direitos fundamentais humanos, haverá um limite para a implantação da flexibilidade e, portanto, não será juridicamente possível se instaurar a chamada flexibilidade absoluta"”.

$\mathrm{O}$ artigo $7^{\circ}$ traz em seu rol a proteção aos direitos dos trabalhadores, e já no seu caput é possível verificar o limite à flexibilização do Direito Laboral, porque além daqueles direitos podem ser concedidos "outros que visem à melhoria de sua condição social", sendo que estes "outros direitos" poderão "advir tanto da produção normativa legislativa quanto negociada". Desta forma, a flexibilização é permitida, observados seus limites, mas não a desregulamentação, porque esta "não representa melhoria de condições ao empregado". Assim, não há nenhum permissivo constitucional expresso para a desregulamentação, valendo "a conclusão de que sua implementação agride frontalmente as cláusulas pétreas constitucionais (art. 60, IV), bem como os princípios Constitucionais da Dignidade Humana e da Valoração Social do trabalho, os quais juntos, preservam os direitos fundamentais trabalhistas" 8 .

Alguns dados da OCDE apontam que a flexibilização da legislação trabalhista precariza de certa forma a relação de emprego acarretando uma diminuição de direitos previstos na legislação trabalhista, bem como verifica-se através dos dados apresentados, que tal instituto facilita a demissão do empregado. Estudos da Organização para Cooperação e Desenvolvimento Econômico (OCDE) apontam que, no período compreendido em novembro do ano de 2009, o desemprego na Espanha obteve percentual de $19,4 \%$, sendo superior 5,4\% com referência ao apontado no ano anterior, na Irlanda, o índice foi na faixa de 5,2\%,

\footnotetext{
${ }^{6}$ PORTO, Lorena Vasconcelos; VIANA, Márcio Túlio. Flexibilização trabalhista e desemprego - a Recente polêmica da Lei de Primeiro Emprego na França. Revista LTr, São Paulo, ano70, n.11, nov. 2006, p. 1336.

${ }^{7}$ MAIOR, Jorge Luiz Souto. O direito do trabalho como instrumento da justiça social. São Paulo: saraiva 2009. p. 181.

${ }^{8}$ BELTRAMELLI Neto, Silvio. Limites da Flexibilização dos direitos trabalhistas. São Paulo: LTr, 2008. P. 77-78.
} 
atingindo 12,9\%. Por fim, na análise dos Estados Unidos, verificou-se o aumento de $3,1 \%$, chegando a $10 \%$.

Em compensação análises realizadas em países nos quais as leis trabalhistas eram mais favoráveis aos trabalhadores, ou seja, prótrabalhadores, a porcentagens de desemprego era menor. Como exemplo, a OCDE cita a Alemanha, com $0,5 \%$ acima da porcentagem analisada no ano anterior, oportunidade em que se verifica 7,6\% de desemprego no mês de novembro, outro exemplo citado é a Itália, a qual alcançou uma ampliação de $1,2 \%$, totalizando $8,3 \%$ de taxa de desemprego no mês de novembro do ano passado, a França, segundo a pesquisa alcançou 1,7 ponto percentual de aumento, atingindo $10 \%$, a Noruega, nesta oportunidade o governo, no período de janeiro de 2009, estipulou algumas medidas que visavam a proteção dos empregos, e em razão das medidas, houve uma evolução de $0,4 \%$ em comparação com o mês de a outubro de 2008, registrando 3,2\% no antepenúltimo mês do ano passado". ${ }^{10}$

Com relação aos países europeus, a Espanha foi o pais que mais "flexibilizou" sua lei trabalhista nos últimos 10 anos, como consequência esta medida gerou altos índices de desemprego, sendo este no patamar de $26,8 \%$, além disso, também houve o aumento da contratação de empregados temporários, sendo este aumento no patamar de $34 \%$, entre os que mais executam este tipo de trabalho estão os jovens e mulheres além de profissionais que possuem menor qualificação. Desta forma resta evidente o aumento da precarização nas relações laborais. Estes trabalhadores normalmente trabalham mais, contudo muitas vezes a remuneração é inferior, além disso estes trabalhadores não usufruem de quase nenhuma proteção de direitos.

O Chile foi outro país que realizou a reforma trabalhista durante o período de 1979, ainda na ditadura de Pinochet, uma das características marcantes foi o aumento considerável do desemprego, atingindo uma alta taxa (20\%). Na Argentina, o processo de flexibilização iniciou-se por volta de 1991, durante o governo Menem, o processo acarretou também a ampliação do desemprego o qual alcançou cerca de $20 \%$ dos indivíduos

\footnotetext{
9 Disponível em: < http://justificando.cartacapital.com.br/2016/09/19/reforma-trabalhista-reduzirdireitos-nao-gera-emprego/. Acesso em 20/06/2.017.

10 Disponível em: < http://justificando.cartacapital.com.br/2016/09/19/reforma-trabalhista-reduzirdireitos-nao-gera-emprego/. Acesso em 20/06/2.017.
} 
bem como ficou contatado que a forma de contratação tornou-se cada vez mais precária, chegando a $85 \%$ anuais ${ }^{11}$.

Os estudos apontam que em uma primeira etapa, a "desregulamentação" volta-se a levar os mercados à exaltação, porém, posteriormente, a economia verdadeira se impõe e se mostra em um ciclo sem fim de recessão e desemprego. Logo chega-se a conclusão que quanto menor o faturamento médio dos trabalhadores, consequentemente menor será o consumo realizado por eles. Assim sendo, diminuindo-se o consumo, por consequência irá se diminuir a produção e, por sucessivamente, a criação de novas vagas de trabalho também fica comprometido.

Logo, é fácil pensar que enquanto for mais "prático" ou enquanto for mais barato demitir um empregado, maior será o número de demissões, tendo em vista que o valor da dispensa para aquele que emprega será muito menor. Assim, quando o empregador face a retração do mercado acredita que a forma mais eficiente de economizar recursos é através da demissão de empregados, principalmente em si tratando de mão-de-obra com menos qualificação.

Outrossim, se o empregador, visando sempre a diminuição de gastos puder exigir de seus empregados uma jornada de trabalho mais extensa pagando o mesmo salário, é visível que o mesmo não irá utilizar de mais recursos com a contratação de outros funcionários para atender toda sua demanda, pelo contrário o empregador irá se utilizar de seus funcionários de forma extraordinária. Assim, verifica-se que não há interesse em novas contratações por parte do empregador.

Desta forma uma das soluções para se rechaçar o desemprego é a redução da jornada, e não o aumento da mesma, sendo que desta forma os próprios empregadores seriam favorecidos com o acréscimo da produtividade do empregado, conforme resta comprovada a sucedida experiência da cidade sueca de Gotemburgo. ${ }^{12}$

Em entrevista reproduzida na revista da $\operatorname{Unisinos}^{13}$, a historiadora Ana Tércia Sanches ressalta que

\footnotetext{
${ }^{11}$ OIT.. Flexibilización en el margen: la reforma del contrato de trabajo, p.11 - por Lygia Maria de Godoy Batista Cavalcanti - "Flexibilização dos direitos trabalhistas: um discurso que não se sustenta".

12 Disponível em: < http://justificando.cartacapital.com.br/2016/09/19/reforma-trabalhista-reduzirdireitos-nao-gera-emprego/. Acesso em 20/06/2.017.

${ }^{13}$ Graziela Wolfart e Thamiris Magalhães, Afirmar que a terceirização gera emprego é um mito, edição 390, 30 de abril de 2012. Disponível em: <
} 


\begin{abstract}
"toda vez que é discutido o instituto da terceirização, bem como a modificação da CLT, empresários utilizam-se do discurso da modernidade, sendo que a opinião sobre o instituto da terceirização sempre vem acompanhado da ideia de que esta modalidade irá gerar novos empregos. Ocorre que tal ideologia não se faz verdadeira, uma vez que não há sustentação técnica, empírica ou estatística. Segundo a historiadora a reforma traz medidas que irão beneficiar os empregadores, visando redução dos custos. Contudo, tal redução se dará as custas dos trabalhadores, tendo em vista que a margem de lucro dos empresários ainda se mantêm alta. logo, o que se verifica é o favorecimento dos empresários, os quais conseguem ter uma maior lucratividade, acúmulo de poder e consequente rentabilidade, as custas dos empregados, que acabam ficando mais pobres.
\end{abstract}

Ademais, o estudioso Márcio Pochmann economista, em artigo publicado na Revista do TST, em julho de 2014, expõe de forma evidente, através de estatísticas, a precarização dos empregos diante da aplicação do instituto da terceirização, vejamos:

"O estudo verificou principalmente com relação à terceirização
desregulada a diminuição de $24,5 \%$ na contração de mão de obra
no Brasil. Contudo, houve a generalização da profissão no mercado
de trabalho, sendo que as condições bem como as relações laborais
mostravam-se inferiores às existentes anteriormente. Quando se
pensa em uma ampliação maior do instituto, como é o caso da
terceirização para as atividades-fim, o risco será o de extermínio do
segmento interno do mercado de trabalho no país, sendo que uma
das principais consequências seria o baixo salário bem como a
grande inconstância nas relações de trabalho e ampla polarização
social". ${ }^{14}$

Assim, diante da análise do texto acima transcrito verifica-se que a diminuição de forma irregular, bem como a retirada de direitos pode ser de certa forma considerada inconstitucional em face dos princípios aplicados a disciplina do direito do trabalho, violando assim cláusulas pétreas. Ademais, constata-se que a retirada de direitos também fere o princípio que veda o retrocesso social. Contudo, a situação econômica contribui com a ideologia de que a diminuição dos direitos acarreta aumento do índice dos empregos. Ocorre que não há nenhuma relação entre o instituto da flexibilização com os parâmetros da empregabilidade.

http://www.ihuonline.unisinos.br/index.php?option=com content $\& v$ view $=$ article $\&$ id $=4385 \&$ secao $=39$ 0. Acesso em 20/06/2.017.

${ }^{14}$ REVISTA DO TRIBUNAL SUPERIOR DO TRABALHO. São Paulo: LexMagister, v. 80, n. 3, jul./set. 2014. $267 \mathrm{p}$. 
Além desses aspectos prejudiciais podemos verificar que a limitação da jornada de trabalho gera muitas vezes o desencadeamento de problemas psicofisiológicos oriundos da fadiga e da excessiva racionalização do serviço, além de acidentes ocupacionais como a LER (lesão por esforço repetitivo). Assim sendo, conforme artigo $6^{\circ}$ da Constituição Federal todos devem viver com dignidade, ser inserido na comunidade, bem como usufruir do Direito Social ao lazer ( Art. 6 cf) à cultura, ao convívio com sua família.

A história em geral demonstra que quanto mais é utilizada a flexibilização na norma trabalhista de um determinado local, maior seria o índice de rotação da mão de obra, sendo desta maneira, maior o índice de desemprego naquela localidade. Ademais, é ainda é visível à existência de diminuição do salário do empregado, bem como tornando precárias as condições laborais.

Conforme pesquisas realizadas, conclui-se que o princípio protetor do Direito do Trabalho nada mais é que uma versão do princípio da irrenunciabilidade, assim como é o entendimento de que quanto ao contrato de trabalho, a regulamentação estatal ou mesmo a convencionada estabelecem para o trabalhador condições mínimas de trabalho, que podem ser ultrapassadas ou melhoradas, porém jamais pioradas ou reduzidas. Adimitindo-se a flexibilidade nas relações de trabalho, empregado e empregador estariam livres para avençar as condições da melhor maneira.

No entanto, diante da dura realidade brasileira, face ao desemprego massivo, os empregados, os desempregados, ou na eminência de o serem, aceitam trocar a aquisição ou a manutenção de um emprego pela dispensa de alguns direitos assegurados pela legislação trabalhista, muitas vezes comprometendo o mínimo de dignidade humana que essa legislação buscou assegurar durante o desenvolvimento do Direito do Trabalho.

A palavra de ordem continua sendo "explorar", porque o empregado depende do emprego para sua subsistência e de sua família. $\mathrm{O}$ empregado, por mais óbvio que pareça, é uma pessoa humana dotada de dignidade, ignorada pelo sistema capitalista, sendo o papel deste sistema somente explorar, cabendo aos autores sociais limitarem sua atuação.

Pregar a livre negociação no discurso parece fácil. Contudo, sob uma ótica mais crítica, a questão que ecoa nas relações de trabalho é: quantos são os empregados que têm "poder de barganha" e podem negociar as condições de trabalho com seus empregadores? 


\section{Conforme expõe José Afonso Dallegrave Neto ${ }^{15}$, cuja a evidência confirma:}

[...] estamos diante de verdadeira cilada. De um lado, os discursos de que o empregado, diante da assistência sindical, estará com forças para negociar de forma igualitária como patrão. De outro, temos a realidade que demonstra o inverso, uma representação sindical imponente, desacreditada e sem poder de representação em face da total desarticulação do movimento operário (...) a propalada flexibilização através da assistência sindical vai beneficiar somente os empregadores; não será diferente a flexibilização negociada diretamente entre a empresa e o trabalhador, pois neste caso o empregador acaba impondo, ao seu talante, as condições de trabalho, tendo o obreiro que aceita-las para não perder a vaga de emprego.

Assim, verifica-se que as medidas flexibilizadoras podem de certa maneira agravar a condição dos hipossuficientes, sem contribuir, de maneira alguma, para o fortalecimento das relações de trabalho.

\section{CONSIDERAÇÕES FINAIS}

Em conclusão, o fenômeno da flexibilização pode ser admitido à luz da Constituição, desde que mediante negociação coletiva e não ocorra a precarização dos direitos trabalhistas, devendo observar o princípio da dignidade da pessoa humana, pois que este princípio é o fundamento de resistência à flexibilização dos direitos fundamentais dos trabalhadores.

\section{REFERÊNCIAS BIBLIOGRÁFICAS}

BELTRAMELLI NETO, Silvio. Limites da Flexibilização dos direitos trabalhistas. São Paulo: LTr, 2008.

BARROS, Alice Monteiro. Curso de direito do trabalho. São Paulo :LTR, 2005.

CORREIA, Marcos Orione Gonçalves. Flexibilização com Fair Play. Revista LTr, São Paulo, ano 65, n. 09 , set. 2001, p. 1048-149.

15 DELEGRAVE NETO, José Afonso O estado neoliberal e seu impacto sócio-jurídico, in Globalização neoliberalismo e direitos sociais Marta Salete Maccaloz ET alli Rio de Janeiro, Editora Destaque, 1997. p. 92. 
DELEGRAVE NETO, José Afonso O estado neoliberal e seu impacto sócio-jurídico, in Globalização neoliberalismo e direitos sociais Marta Salete Maccaloz ET alli Rio de Janeiro, Editora Destaque, 1997. p. 92.

MAIOR, Jorge Luiz Souto. O direito do trabalho como instrumento da justiça social. São Paulo: saraiva 2009. p. 181.

OIT. Flexibilización en el margen: la reforma del contrato de trabajo, p.11 - por Lygia Maria de Godoy Batista Cavalcanti - "Flexibilização dos direitos trabalhistas: um discurso que não se sustenta".

PORTO, Lorena Vasconcelos; VIANA, Márcio Túlio. Flexibilização trabalhista e desemprego - a Recente polêmica da Lei de Primeiro Emprego na França. Revista LTr, São Paulo, ano70, n.11, nov. 2006, p. 1336.

REVISTA DO TRIBUNAL SUPERIOR DO TRABALHO. São Paulo: LexMagister, v. 80, n. 3, jul./set. 2014. 267 p. 